\title{
Enhanced Oxidation of Tetracycline by Permanganate via the Alkali- Induced Alteration of the Highest Occupied Molecular Orbital and the Electrostatic Potential
}

\author{
Dean Song, ${ }^{\dagger, \ddagger \odot}$ Hanyang Cheng, ${ }^{\dagger, \S}$ Ruiping Liu, ${ }^{*}, \dagger, \S$ Zhimin Qiang, ${ }^{\dagger}$ Hong He, ${ }^{\dagger}$ Huijuan Liu, ${ }^{\dagger, \S \odot}$ \\ and Jiuhui $\mathrm{Qu}^{\dagger}$
}

${ }^{\dagger}$ Key Laboratory of Drinking Water Science and Technology, Research Center for Eco-Environmental Sciences, Chinese Academy of Sciences, Beijing 100085, China

${ }^{\ddagger}$ Tobacco Research Institute, Chinese Academy of Agricultural Sciences, Qingdao 266101, China

${ }^{\S}$ University of Chinese Academy of Sciences, Beijing 100049, China

\section{Supporting Information}

ABSTRACT: The reaction between tetracycline and alkaline permanganate was investigated by combining experimental and computational methods. The kinetics was initially studied using a stopped-flow technique and was found to be first-order in tetracycline and permanganate. The second-order rate constant was positive linearly dependent on the concentration of hydroxyl ion $(0.01-0.10 \mathrm{M})$, indicating the presence of base catalysis. By construction of the Eyring plots in the range of 293-308 K, a lower activation barrier $((14.89 \pm 0.44) \mathrm{kcal}$ $\mathrm{mol}^{-1}$ ) was obtained at $298 \mathrm{~K}$ for the base-catalyzed pathway compared with that $\left((17.72 \pm 1.84) \mathrm{kcal} \mathrm{mol}^{-1}\right)$ for the uncatalyzed pathway. The effect of ionic strength further suggested the existence of a complex with higher charge and
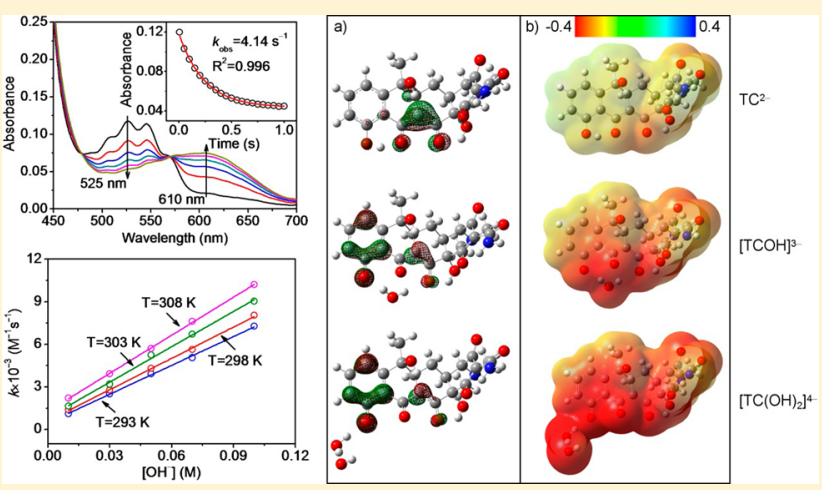
reactivity. It is confirmed by the theoretical analysis that the hydroxyl ion could attract the proton of tetracycline toward itself to form a complex-like structure with a highly reactive phenolate-type moiety. The highest occupied molecular orbital of tetracycline was then transformed from double bond to aromatic ring. The result is supported by the product analysis that the initial oxidation of tetracycline by permanganate occurred predominantly at phenolic group in an alkaline aqueous solution. The base-catalyzed effect was finally explained by electrostatic potential that hydroxyl ion was able to increase the negative charge of tetracycline, making its phenolic group a more electronrich moiety for electrophilic attack.

\section{INTRODUCTION}

Antibiotics were invented to protect people from bacterial infection, but now they have gained increasing attention as an emerging class of environmental pollutants. Tetracycline (TC), one of the most commonly used antibiotics, is employed worldwide in human therapy for controlling diseases and in livestock production for promoting growth. ${ }^{1,2}$ It is reported that the annual consumption of TC has reached more than 5900 tons in the U.S., 2300 tons in Europe, and 9400 tons in China. ${ }^{3-5}$ Due to the high consumption, TC was regularly detected in numerous environmental media including soil, groundwater, surface water, and municipal wastewater. ${ }^{6-9}$ This has inevitably raised the public concern because the long-term exposure to TC may induce the development of antibiotic resistant bacteria and antibiotic resistant genes, which subsequently threatens ecological environment and human health. ${ }^{10}$ Consequently, it is of great importance to develop an efficient technology for TC degradation during water treatment.
As a high-valent metal-oxo species, permanganate anion $\left(\mathrm{MnO}_{4}^{-}\right)$is one of the most versatile and powerful oxidants, widely used in chemistry for applications such as inducing chemiluminescence, preparing functional substances, and establishing chemical oscillation. ${ }^{11-13}$ It is cheap, stable, and also fairly effective against the various emerging pollutants such as phenolic compounds, endocrine disrupting chemicals and antibiotics. ${ }^{14-17}$ In recent years, research on $\mathrm{MnO}_{4}^{-}$has undergone a significant development. The concerted mechanism was recognized to be applicable for the $\mathrm{MnO}_{4}{ }^{-}$oxidation of alkanes and alkenes. ${ }^{18-21}$ The in situ formed manganese species was explored to enhance the transformation of phenolic compounds by $\mathrm{MnO}_{4}{ }^{-14,15}$ However, as a very fundamental issue, the role of hydroxyl ion $\left(\mathrm{OH}^{-}\right)$in the base-catalyzed

Received: January 20, 2017

Revised: March 25, 2017

Accepted: March 30, 2017

Published: March 30, 2017 
$\mathrm{MnO}_{4}{ }^{-}$oxidation remains unclear. Only few studies have speculated that $\mathrm{OH}^{-}$could, for instance, complex with $\mathrm{MnO}_{4}^{-}$ or with the unsaturated bond to form highly reactive intermediates. $^{22-25}$

Owing to both practical and theoretical importance, the TC oxidation by aqueous alkaline $\mathrm{MnO}_{4}{ }^{-}$was examined in this work by combining experimental and computational methods. The reaction kinetics was first determined by a stopped-flow spectrophotometer that allows a continuous monitoring of the fast reaction. ${ }^{26}$ The studies on the reactivity were performed by varying the reaction conditions such as reactant concentration, temperature $(T)$, and ionic strength $(I)$. The kinetic and thermodynamic results were then obtained to elucidate the reaction mechanism. Additionally, the density functional theory (DFT) calculation, which has been proved to be a critical approach in the mechanistic study of chemical reactions, was adopted here to clarify the role of $\mathrm{OH}^{-}$in TC oxidation by $\mathrm{MnO}_{4}{ }^{-19-21,27,28}$ The quantum structures and the corresponding wave functions were supported by the product analysis data and were further used to explain the outcome of kinetic investigation.

\section{EXPERIMENTAL SECTION}

2.1. Chemicals and Materials. Sodium perchlorate $\left(\mathrm{NaClO}_{4}\right)$, sodium hydroxide $(\mathrm{NaOH})$, potassium permanganate $\left(\mathrm{KMnO}_{4}\right)$, and formic acid were at least of analytical grade and purchased from Sinopharm Chemical Reagent Co., Ltd. (Shanghai, China). TC with purity of $96 \%$ was obtained from Jing Ke Hong Da Biotechnology Co., Ltd. (Beijing, China). Acetonitrile at HPLC grade was applied as solvent from Thermo Fisher Scientific (USA). The water used throughout the experiments was purified by a Millipore Milli-Q unit to a final resistivity of $\geq 18.2 \mathrm{M} \Omega \mathrm{cm}$. All working solutions were prepared daily and stored in the dark. $\mathrm{NaOH}$ was employed to provide the required alkalinity and in combination with $\mathrm{NaClO}_{4}$ to maintain the desired $I$.

2.2. Kinetic Studies. An Applied Photophysics stopped-flow spectrophotometer (model SX20, Leatherhead, U.K.) was used to perform the kinetic experiments. Temperature was controlled in the range of $293-308 \mathrm{~K}$ by using an automatic water circulator (Thermo Fisher Scientific, Waltham, MA) connected to the stopped-flow's sample handling unit. The TC concentration was kept in at least 10 -fold excess of that of $\mathrm{KMnO}_{4}$ to maintain the pseudo-first-order condition. For each kinetic run, the reaction was initiated by simultaneously injecting an equal volume of TC and $\mathrm{KMnO}_{4}$ solutions into the optical cell of the stopped-flow. The decay of $\mathrm{MnO}_{4}{ }^{-}$, as denoted by the $525 \mathrm{~nm}$ absorption peak, was continuously monitored. According to the previous study, ${ }^{23}$ kinetic traces were analyzed by using the single exponential equation (Pro-Data software, Applied Photophysics Ltd.):

$$
\mathrm{Abs}_{t}=\left(\mathrm{Abs}_{0}-\mathrm{Abs}_{\mathrm{f}}\right) \exp \left(-k_{\mathrm{obs}} t\right)+\mathrm{Abs}_{\mathrm{f}}
$$

where $k_{\mathrm{obs}}$ represents the pseudo-first-order rate constant; $\mathrm{Abs}_{0}$, $\mathrm{Abs}_{t}$, and $\mathrm{Abs}_{\mathrm{f}}$ are the absorbances at time 0, $t$, and infinity, respectively. Unless otherwise stated, the reported data points represent the mean of three independent experiments. The standard deviations were usually within $5 \%$ and thus were not given in this work.

2.3. Product Studies. The product analysis of the TC oxidation by $\mathrm{KMnO}_{4}$ in alkaline medium $\left(\left[\mathrm{OH}^{-}\right]=0.10 \mathrm{M}\right)$ were implemented at different molar ratios of $\mathrm{KMnO}_{4}$ to TC. After disappearance of the green color, which indicates the characteristic absorption of manganate at $610 \mathrm{~nm}$, the reaction solution was filtered and analyzed by a Waters HPLC system equipped with a Micromass Q-TOF mass spectrometer. Separation was performed on an Agilent C18 column (150 $\mathrm{mm} \times 4.6 \mathrm{~mm}, 3.5 \mu \mathrm{m})$ at a flow rate of $0.2 \mathrm{~mL} \mathrm{~min}^{-1}$ with two mobile phases consisting of $\mathrm{A}$ ( $0.1 \%$ formic acid in water) and $\mathrm{B}$ (acetonitrile). The gradient elution was $0-3 \mathrm{~min}, 95 \% \mathrm{~A}$ and $5 \%$ $\mathrm{B}$; 3-10 min, a linear gradient to $85 \% \mathrm{~A}$ and $15 \% \mathrm{~B} ; 10-25 \mathrm{~min}$, $85 \% \mathrm{~A}$ and $15 \% \mathrm{~B} ; 25-30 \mathrm{~min}$, a linear gradient to $75 \% \mathrm{~A}$ and $25 \% \mathrm{~B} ; 30-35 \mathrm{~min}, 75 \% \mathrm{~A}$ and $25 \% \mathrm{~B}$; $35-40 \mathrm{~min}$, a linear gradient to $60 \% \mathrm{~A}$ and $40 \% \mathrm{~B} ; 40-45 \mathrm{~min}, 60 \% \mathrm{~A}$ and $40 \% \mathrm{~B}$; 45-50 min, a linear gradient to $95 \% \mathrm{~A}$ and $5 \% \mathrm{~B} ; 50-60 \mathrm{~min}$, $95 \% \mathrm{~A}$ and $5 \% \mathrm{~B}$. The ESI-MS analysis was carried out under the positive electrospray ionization mode with a full scan mass range of $m / z=50-1000$. The drying gas was nitrogen at $10 \mathrm{~L} \mathrm{~min}^{-1}$ at $200{ }^{\circ} \mathrm{C}$, and the capillary voltage was $3.5 \mathrm{kV}$.

2.4. Computational Studies. The density functional theory (DFT) calculations were conducted with Gaussian 09 software. $^{29}$ The B3LYP model together with LanL2DZ basis set for the manganese atom and $6-31+\mathrm{G}(\mathrm{d})$ basis set for other atoms was employed throughout this work. The solvent effects in water were taken into account by means of the IEFPCM model. The geometries of all species were fully optimized, and then the vibrational frequencies were calculated for all optimized structures to confirm the nature of the stationary points. The wave function analysis was also implemented in the Gaussian 09 program. The three-dimensional diagrams of optimized structure, the highest occupied molecular orbital (HOMO), and the electrostatic potential were constructed with Gaussview.

2.5. Kinetic Salt Effect. According to the literature, ${ }^{30}$ the reaction scheme of a simple bimolecular reaction can be written as

$$
\mathrm{X}+\mathrm{Y} \stackrel{K}{\leftrightarrow} \mathrm{C}^{++} \stackrel{k^{++}}{\longrightarrow} \mathrm{P}
$$

where $\mathrm{X}$ and $\mathrm{Y}$ represent the reactants; $\mathrm{C}^{++}$represents the transition state; $\mathrm{P}$ represents the product; $\mathrm{K}$ is the thermodynamic equilibrium constant; and $k^{++}$is the reaction rate constant. Thus, the reaction rate can be expressed as

$$
\frac{\mathrm{d}[\mathrm{P}]}{\mathrm{d} t}=k^{++}\left[\mathrm{C}^{++}\right]
$$

By considering the thermodynamic equilibrium

$$
K=\frac{\left[\mathrm{C}^{++}\right]}{[\mathrm{X}][\mathrm{Y}]} \frac{\gamma_{\mathrm{C}^{++}}}{\gamma_{\mathrm{X}} \gamma_{\mathrm{Y}}}
$$

where $\gamma_{X}, \gamma_{Y}$, and $\gamma_{C^{++}}$are the activity coefficients of the relative species, eq 3 can be rewritten as

$$
\frac{\mathrm{d}[\mathrm{P}]}{\mathrm{d} t}=k^{++} K[\mathrm{X}][\mathrm{Y}] \frac{\gamma_{\mathrm{X}} \gamma_{\mathrm{Y}}}{\gamma_{\mathrm{C}^{++}}}=k[\mathrm{X}][\mathrm{Y}]
$$

where $k$ is the second-order rate constant determined experimentally and can be considered as a function of activity coefficients:

$$
k=k^{++} K \frac{\gamma_{\mathrm{X}} \gamma_{\mathrm{Y}}}{\gamma_{\mathrm{C}^{++}}}
$$

For an aqueous solution with $I$ below $0.50 \mathrm{M},{ }^{31}$ the Davies equation can be used to calculate the value of the activity coefficient $(\gamma)$ :

$$
\log \gamma=-A z^{2}\left(\frac{\sqrt{I}}{1+\sqrt{I}}-0.3 I\right)
$$


where $A=0.509$ for water at $298 \mathrm{~K}$ and $z$ is the charge of the ion. Particularly for the transition state $\left(\mathrm{C}^{++}\right)$, the charge number should be the sum of $z_{\mathrm{A}}$ and $z_{\mathrm{B}}$. On the basis of eq 7 , the activity coefficient equals a value of 1 when $I$ is zero. Equation 6 can be then rewritten as

$$
k=k_{0} \frac{\gamma_{\mathrm{X}} \gamma_{\mathrm{Y}}}{\gamma_{\mathrm{C}^{++}}}
$$

where $k_{0}\left(\right.$ i.e., $\left.k^{++} K\right)$ is the second-order rate constant at $I=0$. Substituting eq 7 into eq 8 gives

$$
\log k=\log k_{0}+2 A z_{\mathrm{X}} z_{\mathrm{Y}}\left(\frac{\sqrt{I}}{1+\sqrt{I}}-0.3 I\right)
$$

Equation 9 presents the kinetic salt effect in this work and was utilized to study the effect of $I$ on $k$.

\section{RESULTS AND DISCUSSIONS}

3.1. Reaction Kinetics. 3.1.1. Reaction Order. As shown in Figure 1, the reaction progress of $\mathrm{TC}$ oxidation by $\mathrm{MnO}_{4}{ }^{-}$was

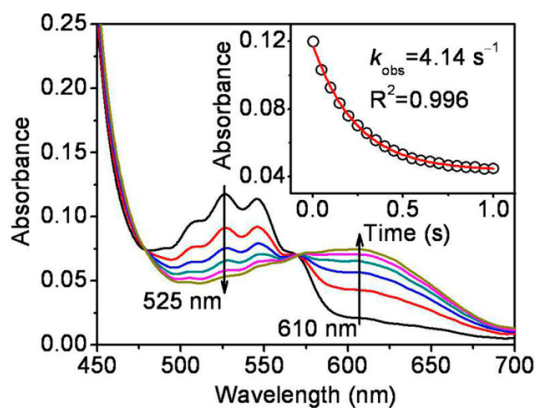

Figure 1. Spectral changes at $0.1 \mathrm{~s}$ time intervals in the oxidation of TC $(0.50 \mathrm{mM})$ by $\mathrm{MnO}_{4}{ }^{-}(0.05 \mathrm{mM})$ with $\left[\mathrm{OH}^{-}\right]=0.10 \mathrm{M}$ and $I=0.11 \mathrm{M}$ at $298 \mathrm{~K}$. Inset: the corresponding kinetic trace at wavelength $525 \mathrm{~nm}$ $\left(\mathrm{Abs}_{0}=0.12\right.$ and $\left.\mathrm{Abs}_{\mathrm{f}}=0.04\right)$.

monitored by a stopped-flow spectrophotometer under pseudofirst-order condition (10-fold excess of TC) with fixed $\left[\mathrm{OH}^{-}\right]$ and $I$. The reduction of $\mathrm{MnO}_{4}{ }^{-}$could be readily identified by the distinct absorbance peak at $525 \mathrm{~nm}$, which was accompanied by an increase of a band with maximum at $610 \mathrm{~nm}$ due to the formed manganate. The inset of Figure 1 shows the decay of $\mathrm{MnO}_{4}{ }^{-}$at $525 \mathrm{~nm}$, which could be fitted well to a single exponential curve as described by eq 1. A plot of the pseudo-first-order rate constant $k_{\mathrm{obs}}$ versus [TC] yields a straight line with a zero intercept (Figure S1 in Supporting Information). These results suggest that the reaction is of first-order with respect to each reactant and second-order in total. Thus, the second-order rate constant $k$ could be obtained by dividing $k_{\text {obs }}$ by [TC].

3.1.2. Effect of $\left[\mathrm{OH}^{-}\right]$. The variation in the values of $k$ was then studied with different $\left[\mathrm{OH}^{-}\right](0.01-0.10 \mathrm{M})$. Figure 2a shows the linear correlation between $k$ and $\left[\mathrm{OH}^{-}\right]$in the range from 293 to 308 K. Similar alkali-dependent behavior was also observed for the reaction of $\mathrm{MnO}_{4}^{-}$with other species. ${ }^{24,32}$ The results suggest the following rate law:

$$
-\frac{\mathrm{d}\left[\mathrm{MnO}_{4}^{-}\right]}{\mathrm{d} t}=\left(k_{1}+k_{2}\left[\mathrm{OH}^{-}\right]\right)\left[\mathrm{MnO}_{4}^{-}\right][\mathrm{TC}]
$$

where $k_{1}$ and $k_{2}$ are the rate constants of the uncatalyzed and base-catalyzed reaction pathways, which can be obtained from the intercepts and slopes of the plots of $k$ versus $\left[\mathrm{OH}^{-}\right]$.
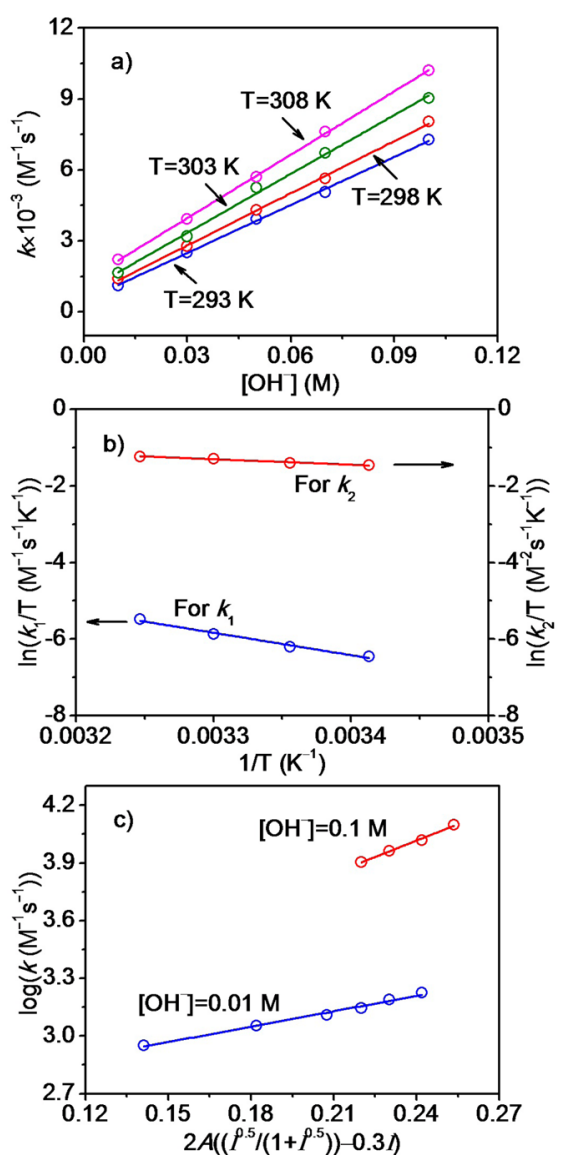

Figure 2. (a) Plots of $k$ versus $\left[\mathrm{OH}^{-}\right]$with $I=0.11 \mathrm{M}$ at $293 \mathrm{~K}$ (blue), $298 \mathrm{~K}$ (red), $303 \mathrm{~K}$ (green), and $308 \mathrm{~K}$ (pink); (b) Eyring plots constructed using $k_{1}$ (blue) and $k_{2}$ (red) with $I=0.11 \mathrm{M}$; (c) effects of $I$ on $k$ with $\left[\mathrm{OH}^{-}\right]=0.01 \mathrm{M}$ (blue) and $\left[\mathrm{OH}^{-}\right]=0.10 \mathrm{M}$ (red) at $298 \mathrm{~K}$ in the oxidation of TC $(0.50 \mathrm{mM})$ by $\mathrm{MnO}_{4}{ }^{-}(0.05 \mathrm{mM})$. The fit parameters for the linear correlations are given in Table S1.

3.1.3. Effect of Temperature. The thermodynamic parameters were further analyzed by constructing the Eyring plots for $k_{1}$ and $k_{2}$ as shown in Figure $2 \mathrm{~b}$. The enthalpy $\left(\Delta H^{++}\right)$and entropy $\left(\Delta S^{++}\right)$of activation were found to be $(11.63 \pm 0.92) \mathrm{kcal} \mathrm{mol}^{-1}$ and $-(20.43 \pm 3.08) \mathrm{cal} \mathrm{K}^{-1} \mathrm{~mol}^{-1}$ for the uncatalyzed reaction pathway and $(2.84 \pm 0.22) \mathrm{kcal} \mathrm{mol}^{-1}$ and $-(40.45 \pm 0.73) \mathrm{cal}$ $\mathrm{K}^{-1} \mathrm{~mol}^{-1}$ for the base-catalyzed reaction pathway. The corresponding free energies of activation $\left(\Delta G^{++}\right)$for the uncatalyzed and base-catalyzed reaction pathways were then determined at $298 \mathrm{~K}$ to be $(17.72 \pm 1.84)$ and $(14.89 \pm 0.44)$ $\mathrm{kcal} \mathrm{mol}^{-1}$, respectively. The lower activation barrier for the basecatalyzed reaction pathway may explain the enhanced reactivity of $\mathrm{TC}$ with $\mathrm{MnO}_{4}{ }^{-}$in the case of higher $\left[\mathrm{OH}^{-}\right]$. In addition, the more negative value of $\Delta S^{++}$also implies the existence of a more unstable transition state for the base-catalyzed process.

3.1.4. Effect of lonic Strength. The influence of $I$ on $k$ was studied with $\left[\mathrm{OH}^{-}\right]=0.01$ and $0.10 \mathrm{M}$ at $298 \mathrm{~K}$. In both conditions, the experimental data in Figure $2 \mathrm{c}$ could be fitted well to eq 9, which was a modification of the Debye-Hückel model suitable for $I<0.50 \mathrm{M}$. The observed slope $\left(z_{\mathrm{X}} z_{\mathrm{Y}}\right)$ of $(2.67 \pm$ $0.14)$ at $\left[\mathrm{OH}^{-}\right]=0.01 \mathrm{M}$ is consistent with a bimolecular reaction between $\mathrm{MnO}_{4}{ }^{-}$and doubly deprotonated $\mathrm{TC}\left(\mathrm{TC}^{2-}\right)$, which comprised more than $99.8 \%$ of TC above $\mathrm{pH} 12$ (Figure S2). However, the slope $\left(z_{\mathrm{X}} z_{\mathrm{Y}}\right)$ of $(5.68 \pm 0.35)$ at $\left[\mathrm{OH}^{-}\right]=0.10$ $\mathrm{M}$ is so large as to suggest the presence of an ion with higher charge. This result also corresponds to the increased 
contribution of the base-catalyzed reaction pathway to $k$ accompanying the increment of $\left[\mathrm{OH}^{-}\right]($Table S2). In particular, the major reaction pathway at $\left[\mathrm{OH}^{-}\right]=0.10 \mathrm{M}$ was the basecatalyzed oxidation of TC by $\mathrm{MnO}_{4}^{-}$, with the contribution equaling 92.4\%. Therefore, it is reasonable to infer that $\mathrm{OH}^{-}$ might combine with $\mathrm{MnO}_{4}^{-}$and/or $\mathrm{TC}^{2-}$ to form a complex with higher charge and reactivity.

3.2. Reaction Mechanism. 3.2.1. Product Analysis. Prior to inquiry of the mechanism of TC oxidation by alkaline $\mathrm{MnO}_{4}^{-}$, the potential product was analyzed based on liquid chromatography-mass spectrometry. The same method has been successfully implemented to characterize the degradation products and to propose the plausible mechanism in the treatment of TC. ${ }^{33-35}$ It should be noted here that though the applied oxidants were variable, the initial reaction sites were always identified to be the phenolic, olefinic, and dimethylamino groups. These are exactly the electron-rich moieties susceptible to electrophilic attack by permanganate. ${ }^{14-17}$ However, in contrast to the previous works, one main product was present accompanied by the abatement of TC in this work as shown in Figure 3. The molecular ion peak was observed at $m / z=459$,
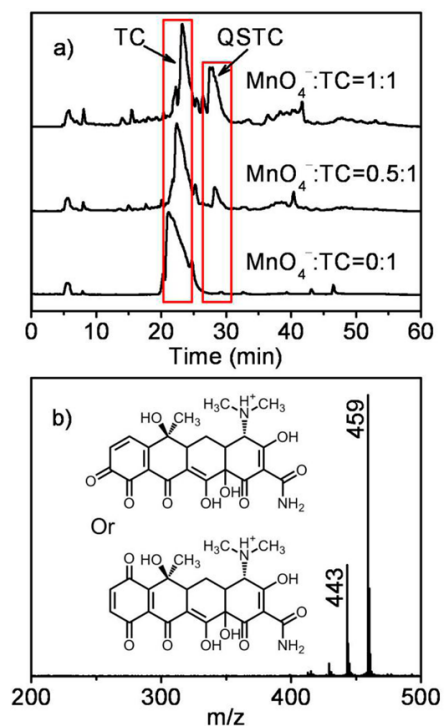

Figure 3. (a) LC-MS chromatograms at different ratios of $\mathrm{MnO}_{4}^{-}$ versus TC; (b) MS spectrum of the major transformation product quinone-substituted TC (QSTC, either ortho or para).

which is in agreement with the characteristic product (ortho or para quinone-substituted TC, QSTC) usually found for TC degradation. ${ }^{34,35}$ The corresponding reaction mechanism should be similar to that described in literature. It is proposed to involve an initial attack of phenolic group on the TC, yielding a precursor diphenol structure with a molecular weight increase of $16 \mathrm{Da}$ (the equivalent of one oxygen atom). The diphenol structure could go through further hydrogen abstraction to afford QSTC with an overall mass gain of $14 \mathrm{Da}$ compared to TC. It is thus reasonable to suggest that the rate-limiting step of TC oxidation by alkaline $\mathrm{MnO}_{4}{ }^{-}$occurred predominantly toward the TC's phenolic group under the $\mathrm{OH}^{-}$-controlled condition.

3.2.2. Quantum Structure Analysis. On the basis of the kinetic and product analysis, structures of the highly reactive species were proposed as below. The preliminary combination of $\mathrm{MnO}_{4}{ }^{-}$and $\mathrm{OH}^{-}$was then assumed to occur in alkaline medium to give a hydroxylated species $\left[\mathrm{MnO}_{4} \mathrm{OH}\right]^{2-}$, which would subsequently decompose to generate $\mathrm{MnO}_{4}{ }^{2-}$ and hydroxyl radical $(\cdot \mathrm{OH}){ }^{22,36}$ This could explain some literature reports but is not applicable here based on the following facts: first, TC should participate in the rate-limiting step of our reaction in view of the first-order dependence on [TC]; second, the reaction rate constant $\left(6.3 \times 10^{9} \mathrm{M}^{-1} \mathrm{~s}^{-1}\right)$ of TC with $\cdot \mathrm{OH}$ is so much larger than the $k$ values $\left(10^{3}-10^{4} \mathrm{M}^{-1} \mathrm{~s}^{-1}\right)$ observed in this study. ${ }^{33}$ Hence, $\left[\mathrm{MnO}_{4} \mathrm{OH}\right]^{2-}$ instead of $\cdot \mathrm{OH}$ was suggested to be a potential oxidant accelerating the reactions. ${ }^{16,23}$ Then we attempted to locate $\left[\mathrm{MnO}_{4} \mathrm{OH}\right]^{2-}$ by performing DFT calculations on the basis of the hypothesized structure. ${ }^{37}$ Figure 4a shows the representative steps of the geometry optimization

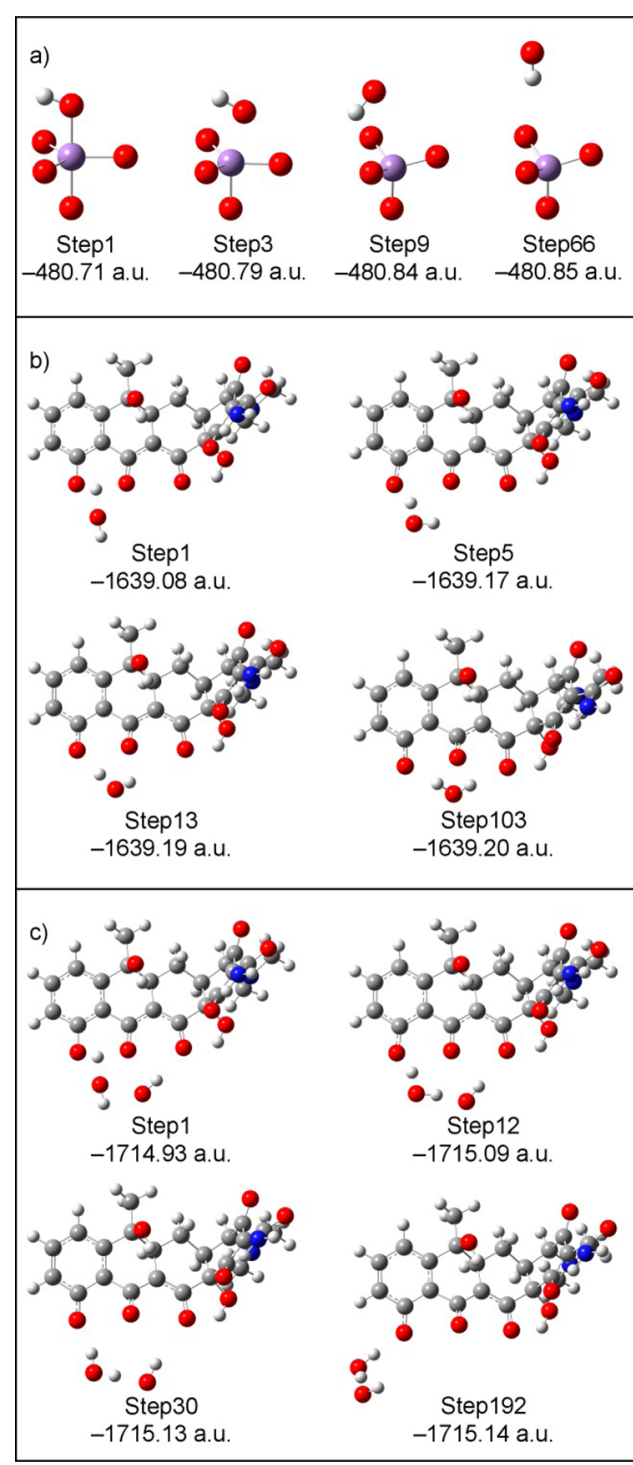

Figure 4. Snapshots of attempted optimizations of the proposed complex: (a) $\left[\mathrm{MnO}_{4} \mathrm{OH}\right]^{2-}$; (b) $[\mathrm{TCOH}]^{3-}$; (c) $\left[\mathrm{TC}(\mathrm{OH})_{2}\right]^{4-}$.

of $\left[\mathrm{MnO}_{4} \mathrm{OH}\right]^{2-}$. The proposed complex dissociated rapidly with an energy decrement of $87.85 \mathrm{kcal} \mathrm{mol}^{-1}$ and finally converged on a hydrogen bond complex (step 66), indicating no existence of $\left[\mathrm{MnO}_{4} \mathrm{OH}\right]^{2-}$ in the reaction.

Formation of a complex between $\mathrm{TC}^{2-}$ and $\mathrm{OH}^{-}$was proposed to be an alternative mechanism for the base-catalyzed $\mathrm{MnO}_{4}{ }^{-}$oxidation. In light of the previous studies, $\mathrm{OH}^{-}$was assumed to be added to the unsaturated bond and/or to be 
coordinated to hydrogen atom. ${ }^{24,25}$ Both could produce more electron-rich species with higher charge. It is also worth noting that the previous similar mechanisms usually have a reaction order of unity on $\mathrm{OH}^{-}$, which is consistent with the data obtained in this work. Therefore, by considering the result of product analysis, we tried to add $\mathrm{OH}^{-}$to the ortho and para positions of the phenolic moiety of TC in DFT calculations. This seems plausible because the aromatic ring has an unsaturated structure and is exactly the site of initial attack by $\mathrm{MnO}_{4}{ }^{-}$. However, all attempts resulted in the immediate departure of $\mathrm{OH}^{-}$from TC and failed to find a stable stationary point (data not shown).

In contrast, the addition of $\mathrm{OH}^{-}$to the vicinity of the phenolic hydroxyl group could successfully produce an optimized structure of $[\mathrm{TCOH}]^{3-}$ (Figure $4 \mathrm{~b}$ ), in which the proton migrated to $\mathrm{OH}^{-}$. This is reasonable because there is a large amount of $\mathrm{OH}^{-}$around the TC molecule in an alkaline medium. An analogous result $\left(\left[\mathrm{TC}(\mathrm{OH})_{2}\right]^{4-}\right)$ could also be obtained by adding a second $\mathrm{OH}^{-}$, as can be seen in Figure 4c. No previous study has reported the possible deprotonation of $\mathrm{TC}^{2-}$ in this $\mathrm{pH}$ range $\left(\left[\mathrm{OH}^{-}\right]=0.01-0.10 \mathrm{M}\right)$. Hence, we proposed that $\mathrm{OH}^{-}$ could just attract the proton to form a complex-like structure with $\mathrm{TC}^{2-}$. The resulting phenolate-type moiety should be more reactive with $\mathrm{MnO}_{4}{ }^{-}$than the phenol moiety of $\mathrm{TC}^{2-38}$

3.2.3. Quantum Wave Function Analysis. To gain a deeper insight into the mechanism, the HOMOs of the proposed structures were plotted as shown in Figure 5a. It is well

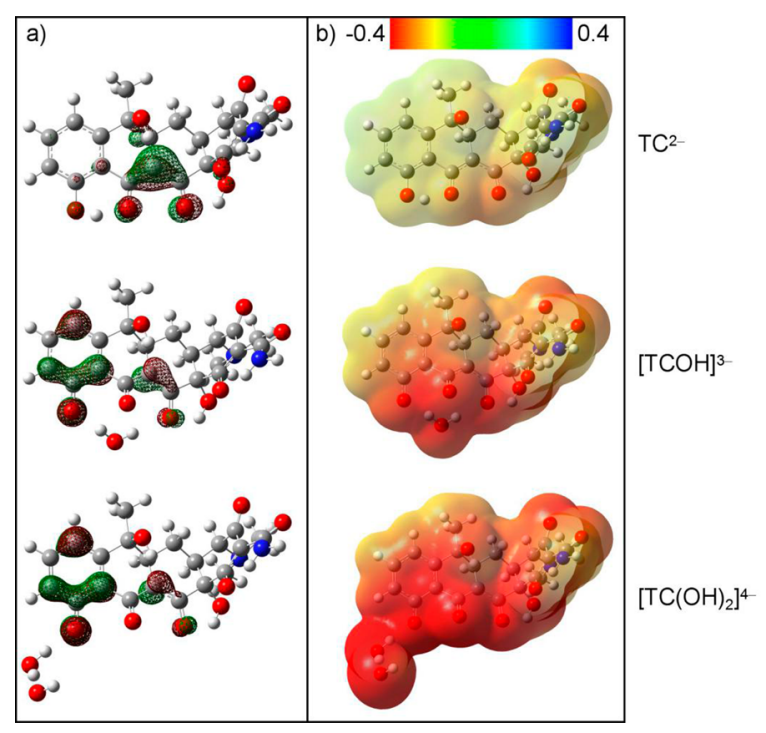

Figure 5. Plots of (a) the HOMO (isovalue $=0.05$ ) and $(\mathrm{b})$ the electrostatic potential (isovalue $=0.001$ ) for the proposed structures of $\mathrm{TC}^{2-},[\mathrm{TCOH}]^{3-}$, and $\left[\mathrm{TC}(\mathrm{OH})_{2}\right]^{4-}$.

established that the frontier orbital theory has been proved as a reliable tool to understand the chemical reactivity. ${ }^{39,40}$ On addition of $\mathrm{OH}^{-}$, the HOMOs of both $[\mathrm{TCOH}]^{3-}$ and $\left[\mathrm{TC}(\mathrm{OH})_{2}\right]^{4-}$ were apt to be localized on the aromatic ring instead of the double bond in $\mathrm{TC}^{2-}$. The result is consistent with that obtained from the product analysis and thus suggests that participation of $\mathrm{OH}^{-}$could alter the regioselectivity of the reaction. The acceleration effect of $\mathrm{OH}^{-}$was further studied by calculating the electrostatic potential of the proposed structures. It has been demonstrated that electrostatic potential is recognized as an effective technique for interpreting and predicting the reactive behavior of molecules. ${ }^{41,42}$ The more negative electrostatic potential usually means the more electron- rich region being susceptible to electrophilic attack. As can be seen in Figure $5 b$, the negative charge on the surfaces of both $[\mathrm{TCOH}]^{3-}$ and $\left[\mathrm{TC}(\mathrm{OH})_{2}\right]^{4-}$ were greatly increased in comparison to that of $\mathrm{TC}^{2-}$. While the $\mathrm{OH}^{-}$was merely located at the vicinity of phenolic hydroxyl group, the increased negative charge was dispersed to a much larger area, thus promoting the reactivity of TC for $\mathrm{MnO}_{4}{ }^{-}$oxidation at the ortho and para positions of the phenolic moiety.

\section{CONCLUSIONS}

We performed experimental and computational experiments to investigate $\mathrm{MnO}_{4}{ }^{-}$oxidation of TC in alkaline aqueous solution. The reaction was found to be overall second-order with firstorder with respect to each reactant. Linear alkali-dependent behavior of $k$ was observed in the range of 293-308 K, indicating the involvement of both uncatalyzed and base-catalyzed pathways. A lower activation barrier was then obtained to explain the higher reaction rate for the base-catalyzed pathway. The results on the effect of $I$ further suggested that $\mathrm{OH}^{-}$tended to combine with $\mathrm{MnO}_{4}{ }^{-}$and/or $\mathrm{TC}^{2-}$ to form a complex with higher charge and reactivity. It is confirmed by the DFT calculations that $\mathrm{OH}^{-}$could attract the proton toward itself to form a complex-like structure with $\mathrm{TC}^{2-}$, resulting in a highly reactive phenolate-type moiety. On the basis of the proposed structures, HOMO of TC was found to be transformed from double bond to aromatic ring, which was exactly the predominant reaction site clearly demonstrated by the product analysis. The base-catalyzed effect was finally disclosed by electrostatic potential that $\mathrm{OH}^{-}$was able to increase the negative charge of TC, making the phenolic group a more electron-rich moiety for electrophilic attack.

\section{ASSOCIATED CONTENT}

\section{S Supporting Information}

The Supporting Information is available free of charge on the ACS Publications website at DOI: 10.1021/acs.iecr.7b00288.

Plot $k_{\mathrm{obs}}$ vs [TC], speciation diagram of TC, fit parameters, and contributions reaction pathways to $k$ in TC oxidation (PDF)

\section{AUTHOR INFORMATION}

\section{Corresponding Author}

*E-mail: liuruiping@rcees.ac.cn.

ORCID $\odot$

Dean Song: 0000-0003-1951-0839

Huijuan Liu: 0000-0003-0855-0202

\section{Notes}

The authors declare no competing financial interest.

\section{ACKNOWLEDGMENTS}

This work was supported by the National Natural Science Foundation for Outstanding Youth Fund (Grant 51422813) and the Qingdao Postdoctoral Application Research Project (Grant 2016105).

\section{REFERENCES}

(1) Daghrir, R.; Drogui, P. Tetracycline antibiotics in the environment: a review. Environ. Chem. Lett. 2013, 11, 209.

(2) Bahrami, F.; Morris, D. L.; Pourgholami, M. H. Tetracyclines: drugs with huge therapeutic potential. Mini-Rev. Med. Chem. 2012, 12, 44. 
(3) U.S. Food and Drug Administration (FDA). Summary Report on Antimicrobials Sold or Distributed for Use in Food-Producing Animals; FDA: Silver Spring, MD, 2014.

(4) Halling-Sørensen, B.; Sengeløv, G.; Tjørnelund, J. Toxicity of tetracyclines and tetracycline degradation products to environmentally relevant bacteria, including selected tetracycline-resistant bacteria. Arch. Environ. Contam. Toxicol. 2002, 42, 263.

(5) Hu, J. Y.; Shi, J. C.; Chang, H.; Li, D.; Yang, M.; Kamagata, Y. Phenotyping and genotyping of antibiotic-resistant escherichia coli isolated from a natural river basin. Environ. Sci. Technol. 2008, 42, 3415.

(6) Wu, N.; Qiao, M.; Zhang, B.; Cheng, W. D.; Zhu, Y. G. Abundance and diversity of tetracycline resistance genes in soils adjacent to representative swine feedlots in China. Environ. Sci. Technol. 2010, 44, 6933.

(7) Lindsey, M. E.; Meyer, M.; Thurman, E. M. Analysis of trace levels of sulfonamide and tetracycline antimicrobials in groundwater and surface water using solid-phase extraction and liquid chromatography/ mass spectrometry. Anal. Chem. 2001, 73, 4640.

(8) Zhang, Q. Q.; Jia, A.; Wan, Y.; Liu, H.; Wang, K. P.; Peng, H.; Dong, Z. M.; Hu, J. Y. Occurrences of three classes of antibiotics in a natural river basin: association with antibiotic-resistant Escherichia coli. Environ. Sci. Technol. 2014, 48, 14317.

(9) Guerra, P.; Kim, M.; Shah, A.; Alaee, M.; Smyth, S. A. Occurrence and fate of antibiotic, analgesic/anti-inflammatory, and antifungal compounds in five wastewater treatment processes. Sci. Total Environ. 2014, 473-474, 235.

(10) Sharma, V. K.; Johnson, N.; Cizmas, L.; McDonald, T. J.; Kim, H. A review of the influence of treatment strategies on antibiotic resistant bacteria and antibiotic resistance genes. Chemosphere 2016, 150, 702.

(11) Lin, Z.; Xue, W.; Chen, H.; Lin, J. M. Classical oxidant induced chemiluminescence of fluorescent carbon dots. Chem. Commun. 2012, 48, 1051.

(12) Yang, S. X.; Yang, H. Y.; Ma, H. Y.; Guo, S.; Cao, F.; Gong, J.; Deng, Y. L. Manganese oxide nanocomposite fabricated by a simple solid-state reaction and its ultraviolet photoresponse property. Chem. Commun. 2011, 47, 2619.

(13) Poros, E.; Kurin-Csorgei, K.; Szalai, I.; Orban, M. Oscillations in the permanganate oxidation of glycine in a stirred flow reactor. J. Phys. Chem. A 2013, 117, 9023.

(14) Jiang, J.; Pang, S. Y.; Ma, J. Role of ligands in permanganate oxidation of organics. Environ. Sci. Technol. 2010, 44, 4270.

(15) Jiang, J.; Pang, S. Y.; Ma, J.; Liu, H. L. Oxidation of phenolic endocrine disrupting chemicals by potassium permanganate in synthetic and real waters. Environ. Sci. Technol. 2012, 46, 1774.

(16) Naik, P. N.; Chimatadar, S. A.; Nandibewoor, S. T. Kinetics and oxidation of fluoroquinoline antibacterial agent, norfloxacin, by alkaline permanganate: a mechanistic study. Ind. Eng. Chem. Res. 2009, 48, 2548.

(17) Cheng, H. Y.; Song, D. A.; Liu, H. J.; Qu, J. H. Permanganate oxidation of diclofenac: the $\mathrm{pH}$-dependent reaction kinetics and a ringopening mechanism. Chemosphere 2015, 136, 297.

(18) Gardner, K. A.; Mayer, J. M. Understanding CH bond oxidations: $\mathrm{H}$. and $\mathrm{H}$-transfer in the oxidation of toluene by permanganate. Science 1995, 269, 1849.

(19) Houk, K. N.; Strassner, T. Establishing the $(3+2)$ mechanism for the permanganate oxidation of alkenes by theory and kinetic isotope effects. J. Org. Chem. 1999, 64, 800.

(20) Strassner, T.; Houk, K. N. Mechanism of permanganate oxidation of alkanes: hydrogen abstraction and oxygen "rebound". J. Am. Chem. Soc. 2000, 122, 7821.

(21) Lam, W. W. Y.; Yiu, S. M.; Lee, J. M. N.; Yau, S. K. Y.; Kwong, H. K.; Lau, T. C.; Liu, D.; Lin, Z. Y. $\mathrm{BF}_{3}$-activated oxidation of alkanes by $\mathrm{MnO}_{4}^{-}$. J. Am. Chem. Soc. 2006, 128, 2851.

(22) Chang, H. S.; Korshin, G. V.; Ferguson, J. F. Investigation of mechanisms of oxidation of EDTA and NTA by permanganate at high pH. Environ. Sci. Technol. 2006, 40, 5089.

(23) Hegde, R. N.; Shetti, N. P.; Nandibewoor, S. T. Kinetic and mechanistic investigations of oxidation of pentoxifylline drug by alkaline permanganate. Ind. Eng. Chem. Res. 2009, 48, 7025.
(24) Freeman, F.; Brant, J. B.; Hester, N. B.; Kamego, A. A.; Kasner, M. L.; McLaughlin, T. G.; Paull, E. W. Permanganate oxidations. III. Kinetics and mechanisms of the oxidation of furfurals in alkaline media. J. Org. Chem. 1970, 35, 982.

(25) Wiberg, K. B.; Freeman, F. Kinetics of the base-catalyzed permanganate oxidation of benzaldehyde. J. Org. Chem. 2000, 65, 573.

(26) Song, D. A.; Liu, H. J.; Qiang, Z. M.; Qu, J. H. Determination of rapid chlorination rate constants by a stopped-flow spectrophotometric competition kinetics method. Water Res. 2014, 55, 126.

(27) Du, H. X.; Lo, P. K.; Hu, Z. M.; Liang, H. J.; Lau, K. C.; Wang, Y. N.; Lam, W. W. Y.; Lau, T. C. Lewis acid-activated oxidation of alcohols by permanganate. Chem. Commun. 2011, 47, 7143.

(28) Song, D. A.; Liu, H. J.; Zhang, A. Q.; Qu, J. H. Fragmentation of typical sulfonamide drugs via heterolytic bond cleavage and stepwise rearrangement. RSC Adv. 2014, 4, 48426.

(29) Frisch, M. J.; et al., Gaussian 09, revision B.01; Gaussian Inc.: Wallingford, CT, 2010.

(30) Atkins, P.; de Paula, J. Physical Chemistry, 9th ed.; Oxford University Press: New York, 2010; pp 849.

(31) Stumm, W.; Morgan, J. J. Aquatic Chemistry: Chemical Equilibria and Rates in Natural Waters, 3rd ed.; Wiley-Interscience, 1996; p 103.

(32) Hassan, R. M.; Fawzy, A.; Alarifi, A.; Ahmed, G. A.; Zaafarany, H. D.; Takagi, H. D. Base-catalyzed oxidation of some sulfated macromolecules: Kinetics and mechanism of formation of intermediate complexes of short-lived manganate (VI) and/or hypomanganate (V) during oxidation of iota- and lambda-carrageenan polysaccharides by alkaline permanganate. J. Mol. Catal. A: Chem. 2011, 335, 38.

(33) Jeong, J.; Song, W. H.; Cooper, W. J.; Jung, J.; Greaves, J. Degradation of tetracycline antibiotics: Mechanisms and kinetic studies for advanced oxidation/reduction processes. Chemosphere 2010, 78, 533.

(34) Chen, W. R.; Huang, C. H. Transformation kinetics and pathways of tetracycline antibiotics with manganese oxide. Environ. Pollut. 2011, 159, 1092.

(35) Ji, Y.; Shi, Y.; Dong, W.; Wen, X.; Jiang, M.; Lu, J. Thermoactivated persulfate oxidation system for tetracycline antibiotics degradation in aqueous solution. Chem. Eng. J. 2016, 298, 225.

(36) Pol, P. D.; Mahesh, R. T.; Nandibewoor, S. T. Free radical intervention in the oxidation of nicotinamide by alkaline permanganate - A kinetic study. J. Chem. Res. 2002, 2002, 533.

(37) Panari, R. G.; Chougale, R. B.; Nandibewoor, S. T. Oxidation of mandelic acid by alkaline potassium permanganate. A kinetic study. J. Phys. Org. Chem. 1998, 11, 448.

(38) Adamczyk, P.; Paneth, P. Theoretical evaluation of isotopic fractionation factors in oxidation reactions of benzene, phenol and chlorophenols. J. Mol. Model. 2011, 17, 2285.

(39) Fukui, K.; Yonezawa, T.; Shingu, H. A molecular orbital theory of reactivity in aromatic hydrocarbons. J. Chem. Phys. 1952, 20, 722.

(40) Lee, M.; Zimmermann-Steffens, S. G.; Arey, J. S.; Fenner, K.; von Gunten, U. Development of prediction models for the reactivity of organic compounds with ozone in aqueous solution by quantum chemical calculations: the role of delocalized and localized molecular orbitals. Environ. Sci. Technol. 2015, 49, 9925.

(41) Politzer, P.; Laurence, P. R.; Jayasuriya, K. Molecular electrostatic potentials: an effective tool for the elucidation of biochemical phenomena. Environ. Health Persp. 1985, 61, 191.

(42) Murray, J. S.; Politzer, P. The electrostatic potential: an overview. WIREs Comput. Mol. Sci. 2011, 1, 153. 